\title{
Erratum to: Serological evidence of bovine herpesvirus-1 (BoHV-1) infection in yaks (Peophagus grunniens) from the National Research Centre on Yak, India
}

Sukdeb Nandi • Manoj Kumar

Published online: 14 April 2010

(C) Springer Science+Business Media B.V. 2010

Erratum to: Trop Anim Health Prob

DOI 10.1007/s11250-010-9526-1

Line "t 1.5 " 50.5 should be read as 50.0

Line "t1.6" 50.0 should be read as 62.6

Table 1 Seroprevalence of BoHV-1 in different sex and age groups of yaks tested by c-ELISA

\begin{tabular}{lllll}
\hline Sex & $\begin{array}{l}\text { Animal } \\
\text { category }\end{array}$ & $\begin{array}{l}\text { Number } \\
\text { of animals } \\
\text { tested }\end{array}$ & $\begin{array}{l}\text { Number } \\
\text { of animals } \\
\text { positive }\end{array}$ & $\begin{array}{l}\text { Seroprevalence } \\
(\%)\end{array}$ \\
\hline Male & Bull & 44 & 25 & 56.8 \\
& Calf & 31 & 21 & 67.7 \\
Female & Heifer & 30 & 15 & 50.0 \\
& Cow & 83 & 52 & 62.6 \\
& Total & 188 & 113 & \\
\hline
\end{tabular}

The online version of the original article can be found at doi:http://dx. doi.org/10.1007/s11250-010-9526-1.

S. Nandi $(\bowtie) \cdot$ M. Kumar

Centre for Animal Disease Research and Diagnosis (CADRAD),

Indian Veterinary Research Institute,

Bareilly, Uttar Pradesh, India

e-mail: snandi1901@yahoo.com 